resembling the folds of a curtain passed rapidly across the northern sky. The light was colourless, with occasional flashes of crimson.

Hoảsock Priory, October 9

H. Mellish

\section{Newton, Wollaston, and Fraunhofer's Lines}

IN most of the current treatises on spectrum analysis, on the spectroscope, and on optics generally (Lloyd's works being exceptions), injustice is done to Newton's care, and scientific insight in his optical experiments, when Wollaston's discovery of the dark lines in the solar spectrum is alluded to, by most positive statements to the effect that Newton never used the slit, or that Wollaston was the first who ever made observations on the pure spectrum.

That the statements are erroneous may be seen by a comparison of the following extracts from Wollaston's paper in the Philosophical Transactions for 1802 , p. 378 , and Newton's

Opticks" edition of I 704.

Wollaston concludes from his experiments that "the colours into which a beam of white light is separable by refraction, appear to me neither 7, as they usttally are seen in the rainbow, nor reducible by any means (that I can find) to 3 , as some persons have conceived, but that by employing a very narrow pencil of light, four primary divisions of the prismatic spectrum may be seen with a degree of distinctness, that, I believe, has not been described nor observed before." He describes the experiment as follows :-

"If a beam of daylight be admitted into a dark room by $a$ crevice $\mathrm{x}-2 \mathrm{O}$ th of an inch broad, and received by the eye at a distance of 10 or 12 feet, through a prism of flint glass free from zeins [italicised by Wollaston], held near the eye, the beam is seen to be separated into the four following colours only, red, vellowish, green, blue, and violet." $\mathrm{He}$ then describes four lines marking these divisions, together with two others for which he does not offer any explanation.

Compare with this Prop. 4 of Book I. of the "Opticks," which is "To separate from one another the heterogeneous rays of compound light." Newton, after showing at some length why he uses a lens to "diminish the mixture of the rays," describes Experiment 11, p, 47, as follows :-

"In the sun's light let into my darkened chamber through a small round hole in my window-shutter, at about ten or twelve feet from the window, I placed a lens, by which the image of the hole might be distinctly cast upon a sheet of white paper. ... Then immediately after the lens I placed a prism, by which the trajected light might be refrac'ed either upwards or sideways." The "oblong image" thus formed he received upon paper placed "at the just distance where the rectilinear sides of the image became most distinct." By varying the size of the hole, he made "the mixture of the rays in the image to be as much or as little as I desired." For this purpose he caused the breadth of the image to be sometimes sixty or seventy times less than its length.

"Yet insteal of the circular hole, 'tis better to substitute an oblong hole shaped like a long parallelogram, with its length parallel to the prism. For if this hole be an inch or two long, and but a tenth or twentieth part of an inch broad or nar rower; the light of the image will be as simple as before, or simpler, and the image will become much broader, and therefore more fit to have experiments tried in its light than before."

For the purpose of comparing the simpler light with the more compound, he used also a hole of the shape of an isosceles triangle, whose base was "about the tenth part of an inch, and its height an inch or more" (the width of which, therefore, at a quarter of an inch from the vertex, would be one-fortieth of an inch). The refracting edge of the prism was parallel to the perpendicular of the triangle. The images would therefore be "equicrural triangles," "a little intermingled at their bases, but not at their vertices."

$\mathrm{He}$ is very emphatic as to the precautions in making the experiments. He was always careful to have the image in the position of minimum deviation-all foreign light must be carefully excluded from the chamber. The lens must be good-the prism being made of "glass free from bubbles and veins," with its sides truly plane and its polish elaborate." "The edges also of the prism and lens, so far as they make any irregular refraction, must be covered with a black paper glued on." "It's difficult to get glass prisms fit for this purpose."

He did not, as is sometimes supposed, always receive the images on paper, for in Expt. 4, Prop. ii., p. 22, he says: "I looked through the prism upon the hole."

That with good prisms, and the great variety of experiments which he must have tried, he did not see the dark lines by looking through the prisms, seems remarkable. It may possibly be explained by the fact that in the very class of experiments in which he was most likely to discover the lines (and in which Wollaston actually discovered them), he found himself obliged to rely on the observation of an assistant. This is mentioned on p. 92 in Prop. iii. of the second part of Book I. The proposition is "To define the refrangibility of the several sorts of homogeneal light, answering to the several colours." In this he says : "I delineated therefore in a paper the perimeter of the spectrum"... " and held the paper so that the spectrum might fagll upon this delineated figure, and agree with it exactly, whilst an assistant, whose eyes for distinguishing colours were more critical than mine, did by right lines drawn across the spectrum note the confines of the colours."

McGill College, Montreal, Canada, September 19

\section{The Spectroscope and Weather Forecasting}

I MUCH regret that Prof. Smyth should have taken the word prognostic, applied to the rain-band as a depreciatory epithet, when it was only intended as a term of classification. In common parlance any particular "look" of the sky is called a $\operatorname{prog}_{i}$ ostic, and it is a natural extension of the idea to call the "look" of the sky absorption a spectrum prognostic also.

The question at issue is this. Assuming that the rain-band is a quantitative measure of the amount of vapour in a section of the atmosphere, why is it of more use in forecasting than the numerous sky and other prognostics which also indicate an excessive amount of vapour, as, for instance, sweating walls, or a soft sky. Like them, it precedes rain in certain cases, and for the same reason; like them, it fails in numerous cases where rain falls without being preceled by excessive vapour quantity; and, like them, it cannot compare in forecasting value with synoptic observations over a large area, which correlate moist currents with isobaric lines.

But there is one case in which the rain-band may give valuable information-when we have a vapour-laden upper current over a dry surface wind. This often occurs in winter, with a warm south-west current over an area of frost and an east wind. In practice this almost invariably makes itself visible by the long converging stripes of cirrus which so often precede a rainy thaw, but still cases may occur when no cirrus is formed, or it is otherwise invisible. Here is a case in point. One spring morning in London there was a thick fog, with a south-west wind. About I a.m. the wind shifted to east, the pavement remaining white and dry ; when, to my surprise, the ordinary spectrum of a fog was crossed by a strong rain band. Two hours afterwards a few big drops of rain fell, which soon ceased, and the wind returned to the south-west.

The $8 \mathrm{a} . \mathrm{m}$. chart showed London to be then on the northern edge of an anticyclone, with a small secondary cyclone over Devonshire; this moved on during the day, bringing rain with it, which soon passed.

We can now estimate the different values of the several indications. Cirrus, if there is any, tells that a moist south-west upper current has set in, but not if it is specially vapour-laden.

The rain-band tells us simply that there is an abnormal amount of vapour somewhere, and roughly measures it; by inference, from the dryness of the ground, we know that the vapour must be overhead; in very rare cases the band would speak before the cirrus, and in any case would show unusual vapour, which the cirrus could only suggest by looking softer than usual. On the other hand, the spectroscope would be silent in numberles cases where cirrus would indicate rain correctly, and neither could tell their story till the vapour-bearing current had set in.

' 1 he forecaster, who used synoptic charts, would know that a ramp south-west wind always blew over the north-east wind in front of a cyclone, and in a case like this could say that as the secondary approached, the moist upper current would set in some hours before it arrived, and would be so far ahead of any prognostic; but he would have no means of saying if the current was extra vapour-laden or not.

But in most cases a knowledge of the fact would be but of little service to him. Suppose that in this case tleere was rain at Plymouth, cirrus or rain-band at Portsmouth, and blue sky over 